\title{
EPIDEMIOLOGICAL AND CLINICAL CHARACTERISTICS OF CHILDREN WITH MEASLES HOSPITALIZED AT THE DEPARTMENT FOR INFECTIOUS DISEASES IN TUZLA DURING THE 2014-2015 MEASLES EPIDEMIC
}

\author{
Rahima JAHIĆ, Humera POROBIĆ-JAHIĆ, Denis ŽEPIĆ
}

The Department for Infectious Diseases University-Clinical Center Tuzla, Tuzla Bosnia and Herzegovina

\author{
Correspondence: \\ rahima.jahic@ukctuzla.ba \\ Tel.: + 38735303327 \\ Fax.: + 38735303480
}

Received: December 6, 2016 Accepted: February 15, 2017

Key words: Measles • Outbreak • Children - Hospitalization.

\begin{abstract}
Objective - The aim of this paper is to present the epidemiological and clinical characteristics of a measles outbreak in children age 0-18 years, who were hospitalized at the Clinic for Infectious Diseases of the University Clinical Center, Tuzla in the 2014/2015 period5. Patients and methods - The target population of this retrospective study were patients in the 0-18 year age group, who were hospitalized at the Clinic for Infectious Diseases during the measles outbreak in 2014/2015. Results - At the Clinic for Infectious Diseases in Tuzla, 341 patients with the clinical characteristics of measles were hospitalized during the period of the measles outbreak in 2014/2015. Of all hospitalized patients $74.7 \%$ (255/341) belonged to the age group from 0 to 18 years. Most of hospitalized children, $146(57.2 \%)$ of them, were in the age group from 0 to 6 years, next was the group of children aged 11 to 18 years, $69(27.1 \%)$ of them, followed by the group of children aged from 6 to 10 years, 40 (15.7\%) of them. Complications were present in 176 (69.02\%) of the hospitalized children. Among the hospitalized children suffering from measles, $92.5 \%$ were unvaccinated or incompletely vaccinated, or their vaccination status was unknown. Conclusion - The youngest population is susceptible to a much higher risk of measles. To reduce the incidence of measles in children a high level of immunization is required.
\end{abstract}

\section{Introduction}

Measles, rubeola, or red measles (lat. morbilli - "little disease") is a viral, highly contagious disease from the group of rush diseases, which mainly affects children. The disease is clinically manifested by general weakness, fever, inflammatory changes in the conjunctiva, the mucous membrane of the respiratory organs and the appearance of rash (1). Newborns are protected in the first six months of life by passive immunity, transferred from the mother, but only if she is immune, vaccinated or has recovered from measles. In 1963, before the application of immunization against measles began, the disease was widespread, with about 2.6 million deaths worldwide. The mortality rate was highest in some countries of Africa (2). Therefore, the World Health Organization (WHO) set the obligation known as the "Millennium Development Goal" to reduce the number of deaths among children from measles by two-thirds by 2015, in respect of the level of 1990. It was estimated in 2009 that 
in developing countries measles affects about 30 million children per year (2). The number of reported outbreaks of measles, especially in central, western and south-eastern Europe, has increased in the last five years $(3,4)$.

About $30 \%$ of reported cases of measles include one or more complications. In developed countries, most common complications are middle ear inflammation (7-9\%), inflammation of the lung (1-6\%), diarrhea $(6 \%)$, blindness and post infectious encephalitis (1 in 1000 cases). The risk of serious complications is higher in infants than in adults (5). A very high level of immunity in the populations of most countries was achieved by vaccination, which led to the elimination of the disease in many countries. According to the CDC in the United States, there is an average of 63 measles cases reported per year.

However, if the level of population immunity is not maintained constantly at a high level, 95\%, a new (cyclic) occurrence of outbreaks of measles is possible (6). In our country, children have been vaccinated against measles since 1970, and since 1981 the combined measles-mumps-rubella (MMR) vaccine has been in use, as recommended by the WHO (7). Due to the war (1992-1995), the great migrations of the population, and the movement against vaccination, there was a large drop in vaccine coverage and this made it possible for a measles outbreak to occur in the Federation of Bosnia and Herzegovina (FBA) in 2007 (8). The aim of this study was to analyze the epidemiological and clinical characteristics of the measles outbreak in children aged 0-18 years, hospitalized at the Clinic for Infectious Diseases UCC Tuzla, in 2014/2015.

\section{Patients and methods}

By means of a retrospective study we analyzed the medical records of the Clinic for Infectious Diseases in Tuzla concerning the patients aged $0-18$ years that were treated for the diagnosis of measles during an epidemic of the disease (9), from June 2014 to September 2015. The diagnosis of measles was based on medical history and clinical findings, using the "case definition of suspected measles" (generalized maculopapular rash and fever plus the presence of one or more of the following symptoms or signs of disease: cough, conjunctivitis or a patient who had clinically suspected measles) (10), an Elisa test done 10 days from infection, and a serological finding indicating the presence of IgM antibodies. We took nasopharyngeal swabs and serum, which were analyzed by the PCR method. Adequate immunization of measles was defined as documented proof of vaccination in the 13th month of life, and revaccination in the sixth year. The results are shown in the absolute and relative numbers.

\section{Results}

An outbreak of measles in the Tuzla Canton (TK) lasted from 23.06.2014 to 11.09.2015. 1,396 infected people were registered. Of that number, 341 people were hospitalized at the Clinic for Infectious Diseases, of whom $74.7 \%(255 / 341)$ were in the age group up to 18 years. The largest number of hospitalized children, 146 of them, or $57.2 \%$, were aged up to six years, followed by 69 or $27.1 \%$ aged $11-18$ years, while there were 40 or $15.7 \%$ aged 6-10 years. The average length of hospital stay was $7.66 \pm 2.79$ days.

The distribution of hospitalized children in terms of their place of residence in the Tuzla Canton was as follows: the largest number was from the municipality of Lukavac, $27.4 \%(70 / 255)$, followed by Tuzla with $24.3 \%$ (62/255), then with Živinice, 15.6\% (40/255), Kladanj 8.6\% (22/255), Banovići 7.8\% (20/255), Gračanica 6.3\% (16/255), Gradačac 4.3\% (11 / 255), Srebrenik 2.3\% (6/255), Kalesija 1.2\% (3/255), Sapna and Doboj Istok with 0.8\% (2/255) and Teočak with $0.4 \%$ (1/255). Fig. 1 shows the seasonal incidence of measles in children hospitalized 


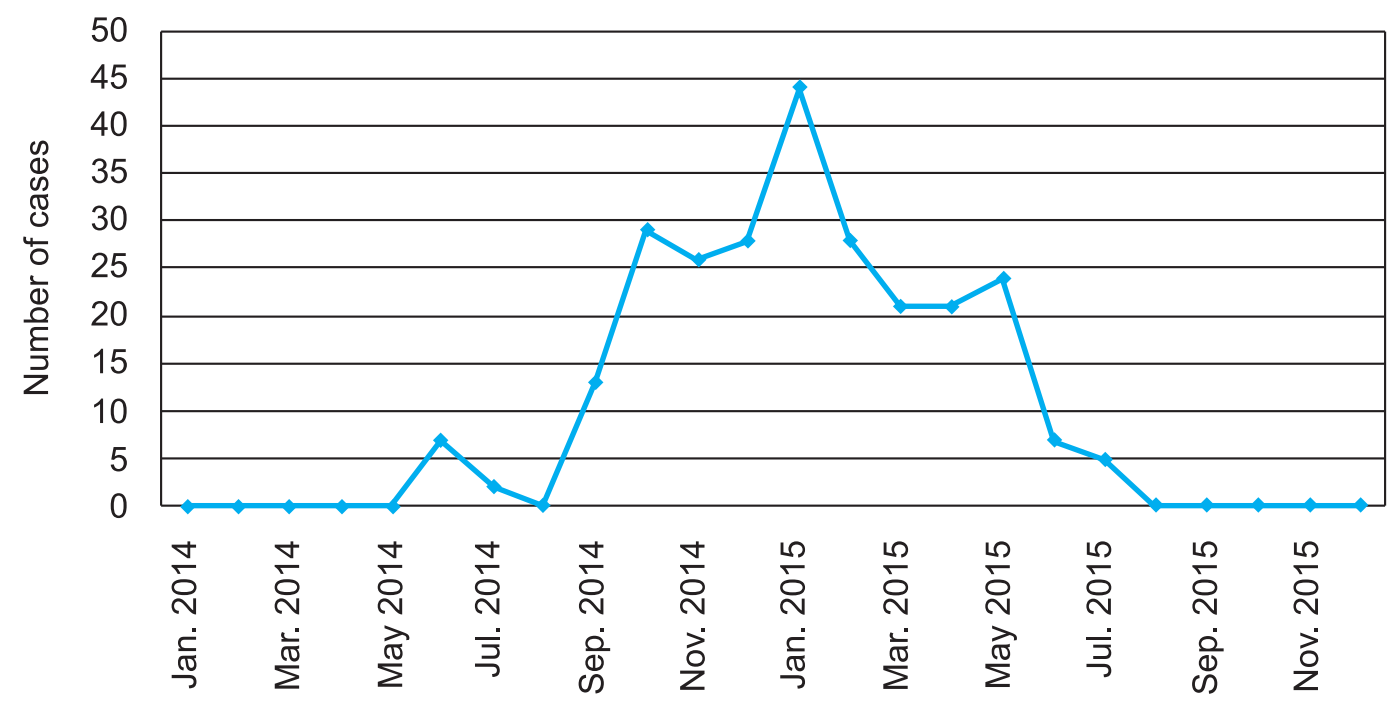

Fig. 1 Seasonal incidence of measles in children hospitalized at the Clinic for Infectious Diseases in Tuzla during the measles outbreak from June 2014 to September 2015.

\begin{tabular}{|c|c|c|c|c|c|c|}
\hline \multirow{4}{*}{$\begin{array}{l}\text { Symptoms } \\
\text { and signs }\end{array}$} & \multicolumn{6}{|l|}{ Patients } \\
\hline & \multicolumn{5}{|c|}{ Age groups (Years) } & \multirow{3}{*}{$\begin{array}{l}\text { Total } \\
\mathrm{n} ;(\%)\end{array}$} \\
\hline & $<1$ & $1-4$ & $5-9$ & $10-14$ & $15-18$ & \\
\hline & $(\mathrm{n}=29)$ & $(\mathrm{n}=105)$ & $(n=45)$ & $(\mathrm{n}=37)$ & $(\mathrm{n}=39)$ & \\
\hline Fever & 29 & 104 & 45 & 37 & 39 & 254 (99.6) \\
\hline Rash & 29 & 105 & 43 & 36 & 39 & $252(98.8)$ \\
\hline Cough & 23 & 97 & 40 & 34 & 37 & $231(90.6)$ \\
\hline Anorexia & 20 & 63 & 27 & 25 & 30 & $165(64.7)$ \\
\hline Conjunctivitis & 15 & 60 & 27 & 25 & 29 & $156(61.2)$ \\
\hline Weakness & 9 & 55 & 28 & 21 & 24 & $137(53.7)$ \\
\hline Runny nose & 15 & 72 & 19 & 10 & 13 & $129(50.6)$ \\
\hline Koplik's spots & 7 & 39 & 16 & 17 & 13 & $92(36.1)$ \\
\hline Vomiting & 7 & 22 & 9 & 19 & 12 & $69(27.1)$ \\
\hline Diarrhea & 7 & 25 & 6 & 8 & 12 & $58(22.7)$ \\
\hline Sore throat & 0 & 1 & 10 & 14 & 22 & $47(18.4)$ \\
\hline Hepatomegaly & 6 & 18 & 8 & 1 & 6 & $39(15.3)$ \\
\hline Lymphadenitis & 6 & 12 & 3 & 2 & 8 & $31(12.2)$ \\
\hline Headache & 0 & 1 & 4 & 6 & 10 & $21(8.2)$ \\
\hline
\end{tabular}

at the Clinic for Infectious Diseases during the measles outbreak from 2014 to 2015 . The highest number of hospitalizations was in the winter, while in summer the number of hospitalizations was much lower.
By analyzing the vaccination status it was found that $3.5 \%(9 / 255)$ of the patients received two doses of vaccine, 4.0\% (10/255) a single dose of vaccine, $22.3 \%(57 / 255)$ were not vaccinated and for $70.2 \%(179 / 255)$ of 
Table 2 The frequency of complications in children hospitalized at the Department for Infectious Diseases in Tuzla during the measles outbreak in 2014/2015

\begin{tabular}{|c|c|c|c|c|c|c|}
\hline \multirow{3}{*}{ Complications } & \multicolumn{6}{|c|}{ Age groups (Years) } \\
\hline & $<1$ & $1-4$ & $5-9$ & $10-14$ & $15-18$ & \multirow{2}{*}{$\begin{array}{l}\text { Total } \\
\mathrm{n} ;(\%)\end{array}$} \\
\hline & $(\mathrm{n}=29)$ & $(\mathrm{n}=105)$ & $(\mathrm{n}=45)$ & $(\mathrm{n}=37)$ & $(n=39)$ & \\
\hline Pneumonia dex. & 9 & 51 & 21 & 10 & 8 & $99(38.8)$ \\
\hline Pneumonia bil. & 6 & 24 & 6 & 4 & 2 & $42(16.5)$ \\
\hline Pneumonia sin. & 2 & 7 & 6 & 1 & 1 & $17(6.7)$ \\
\hline Bronchitis & 2 & 4 & 1 & 3 & 1 & $11(4.3)$ \\
\hline Sinusitis & 0 & 1 & 0 & 1 & 1 & $3(1.2)$ \\
\hline Laesio hepatis & 0 & 0 & 0 & 0 & 3 & $3(1.2)$ \\
\hline Encephalitis & 0 & 0 & 0 & 0 & 1 & $1(0.4)$ \\
\hline
\end{tabular}

patients data on vaccination were not known. The frequency of symptoms and signs are shown in Table 1 . The most common manifestations of disease were fever, rash and cough, while other manifestations were present in a significantly smaller number.

Complications of the disease were found in $176(69.02 \%)$ hospitalized children, of which one child had encephalitis, 158 (62\%), pneumonia, 11 (4.3\%), bronchitis, while in three children (1.2\%) sinusitis and elevated transaminase were registered (Table 2).

Of the 255 hospitalized children $38.4 \%$ were discharged as cured, while $61.5 \%$ were discharged as improved. Diagnosis of measles was confirmed in 17 of 18 (7.06\%) hospitalized children tested by serological testing, while in the others the diagnosis was based on clinical and epidemiological data.

\section{Discussion}

During the measles outbreak in the Tuzla Canton, three-quarters of patients who were hospitalized were younger than 18 years. More than half of the hospitalized were children aged younger than 6 years, which suggests that there is a significant gap in immunization in this age group, probably due to the accumulation of susceptible individuals over several years. A similar age represen- tation is evident in the recent outbreaks in Europe, which showed a higher proportion of cases (64\%) among patients younger than five years. Several countries have reported a significant number of cases of measles, including: France, Bulgaria, Germany, Italy, Romania, Spain, Ukraine and the United Kingdom (3, 4, 11). In France, the highest incidence was observed in the age group up to one year (12). Since the beginning of 2014 , in an epidemic of measles in the FBA, there were a total of 3,804 cases to February 2015 (9). According to the European Centre for Disease Prevention and Control, in 30 EU / European Economic Area (EEA) countries, in the, supervision of measles in total 3,840 cases were reported between December 2013 and November 2014 (11).

It is interesting to note that more than a quarter of the hospitalized children in our study were aged 11-18 years. Children at this age are socially more active than others and are thus more exposed to the risk from viral infection. Also, this age group is more sensitive, due to the war and post-war period, and the later antivaccinal movement that contributed to indecisiveness in parents, and led to major gaps in the coverage by the vaccine. Similar results were reported in the epidemic in Peru, where it affected $56 \%$ of children aged up to 15 years, and where vaccine cover- 
age is low (13). In this study, a significant factor in the transmission of measles are adults aged over 15 years.

The numbers of reported cases and hospitalized patients differed between municipalities. More than half of the hospitalized children were from the two municipalities Tuzla and Lukavac, while fewer children were hospitalized from more distant municipalities. This would indicate that the health service is less accessible among the residents of border areas of TC. On the other hand, it is possible that the populations of rural and marginal municipalities was previously immunized, or that due to remoteness they were less affected by this epidemic.

In our region measles shows a seasonal character of occurrence, with a peak of morbidity in the fall, winter and spring. The seasonal character is even more pronounced in the study of the epidemic of measles in Ethiopia (14), where a higher number of cases were recorded in February and March. Seasonal variations in a measles epidemic were also recorded in Nigeria during July, August and September (15). The authors of the study associated this phenomenon with the movement of people and traditional ceremonies (weddings, religious festivals) in the season, when favorable conditions are created for the transmission of measles virus.

Among the hospitalized children suffering from measles in our study, only $4 \%$ were vaccinated, while others were unvaccinated or incompletely vaccinated, or their vaccination status was unknown. All this points to the existence of fear of complications of the vaccine, deficiencies in health education of the population, and poor monitoring of the effectiveness of immunization status. Even more confusing is the fact that in our country vaccination is legally required (16), while for instance in most countries of the European Union vaccinations are not required, but the relevant state institutions recommend vac- cination whilst notifying parents of the possible adverse effects of vaccination. Nevertheless, the coverage there is better than in this part of the world.

In an outbreak of measles in Peru, only $4.2 \%$ of children aged 6 months to 10 years were vaccinated, which is explained by the fact that vaccinating children is not a public health priority, and there is poor access to adequate health care services (13). According to the WHO, vaccination coverage in the Africa Region is in the range of $77 \%$ to $93 \%$ (17). Measles is endemic in Africa, and the goals of the WHO are focused on improving control and achieving high immunization coverage, in order to reduce the incidence to less than one case per million of the total population by 2020 in Africa.

In our patients, the most common manifestations of the disease were fever, rash and cough, which is the common clinical picture of measles. In the epidemic in Peru, clinical manifestations were different, so that diarrhea was the most common (60.7\%), followed by conjunctivitis, sore throat and headache (13). It is interesting that in the transmission of the measles virus social events, (such as baptisms and funerals) have a specific role, when there is a large grouping of a population, and mostly low-income and vulnerable people become more susceptible to viruses. The most common complication in our patients was pneumonia, registered in more than half of the hospitalized children. More severe complications and deaths were not registered.

Pneumonia appears as a complication in about $30 \%$ of patients and at the time before the discovery of antibiotics, it was often deadly. At the present time (unfortunately only in developed countries), when bacterial complications are successfully treated with antibiotics, mortality is significantly lower (is about 1 per 1,000 patients) and is caused by the influence of the virus, primarily on the central nervous system, where it actually occurs 
due to encephalitis (5). However, data on the probability of death and severe complications are mentioned in other studies $(14,18)$.

In 2010, over 30,000 cases of measles were reported in 32 European countries, according to reporting euvac.net (of which $72 \%$ were reported from Bulgaria and 17\% in France), and 24 cases resulting in death in Bulgaria, 2 in France, and one in Romania (19).

\section{Limitation of study}

Our study had several limitations. First, our estimates of immunization coverage are based on administrative data, which depend on the validity of the documentation, because it can only provide a relative assessment of immunization coverage. Second, serological confirmation of the diagnosis was conducted in only $7 \%$ of hospitalized children, which was sufficient for declaring the epidemic. Finally, our results may not be representative of all cases of measles, because certain areas of our Canton have a good surveillance system and the population has better access to health care institutions, in relation to others. Also, given that we did not have data on the age distribution of children in Tuzla Canton for 2014/2015, age-specific rates were not shown.

\section{Conclusion}

Among the hospitalized children who were suffering from measles, $92.5 \%$ were unvaccinated or incompletely vaccinated, or their vaccination status was unknown. This epidemic is a direct result of the failure in the vaccination program during the war period, 1992-1995, as well as the non-vaccination of children in later years, and the appearance of a large number of people susceptible to measles. Programs of prevention, control and elimination of measles and other diseases are required to contain a component that relates to the health education of the population. A high percentage of vaccination with two doses of vaccine, advocacy for communication campaigns and the effective involvement of the community and the public are essential for avoiding future epidemics.

Conflict of interest: The authors declare that they have no conflict of interest.

\section{References}

1. Forni AL, Schluger NW, Roberts RB. Severe measles pneumonitis in adults: evaluation of clinical characteristics and therapy with intravenous. Clin Infect Dis. 1994;19(3):454-62.

2. World Health Organisation. Global reductions in measles mortality 2000-2008 and the risk of measles resurgence. Wkly Epidemiol Rec. 2009;84:505-16.

3. World Health Organization. 9th Meeting of the Measles/Rubella Reference Laboratories of the WHO European Region, 10-11 March 2014, Copenhagen, Denmark. Copenhagen: WHO/Europe; 2014.

4. Santibanez S, Prosenc K, Lohr D, Pfaff G, Jordan Markocic O, Mankertz A. Measles virus spread initiated at international mass gatherings in Europe, 2011. Euro Surveill. 2014;19(35):20891.

5. Strebel PM, Papania MJ, Dayan GH, Halsey NA. Measles vaccine. In: Plotkin SA, Orenstein WA, editors. Vaccines. 5th ed. Philadelphia: Elsevier Inc; 2008. p. 353-98.

6. World Health Organisation, European Region. Measles and Rubella. Surveillance Guidelines for Measles, Rubella and Congenital Rubella Syndrome in the WHO European Region; 2007.

7. World Health Organization. Measles vaccines: WHO position paper. Wkly Epidemiol Rec. 2009;35:349-60.

8. Kremer JR, Brown KE, Jin L, Santibanez S, Shulga SV, Aboudy Y, et al. High genetic diversity of measles virus, World Health Organization European Region, 2005-2006. Emerg Infect Dis. 2008;14(1):107-14.

9. Hukic M, Ravlija J, Karakas S, Mulaomerovic M, Dedeic Ljubovic A, Salimovic-Besic I, et al. An ongoing measles outbreak in the Federation of 
Bosnia and Herzegovina, 2014 to 2015. Euro Surveill. 2015;20:21047.

10. European Centre for Disease Prevention and Control (ECDC). EUVACnet. Case Definition. Measles. Stockholm:ECDC. [updated 2012 Aug 8; cited 2016 Dec 15]. Available from: http://ecdc. europa.eu/en/activities/surveillance/euvac/case_ definition/Pages/measles.asp.

11. European Centre for Disease Prevention and Control (ECDC). Number of measles cases by month and notification rate (cases per million) by country, December 2013 - November 2014, EU/EEA countries. Stockholm: ECDC. [updated 2015 Jan 26; cited 2016 Dec 15]. Available from: http:// www.ecdc.europa.eu/en/healthtopics/measles/epidemiological_data/Pages/measles_past 12 months. aspx.

12. European Center for Disease Prevention and Control (ECDC). Epidemiological update on measles in EU/EEA. Current situation in France 2011. [updated 2011 Jun 20; cited 2016 Dec 14]. Available from: http://www.ecdc.europa.eu/en/activities/sciadvice/Lists/ECDC.

13. Sniadack DH, Moscoso B, Aguilar R, Heath J, Bellini W, Chiu MC. Measles epidemiology and outbreak response immunization in a rural community in Peru. Bull World Health Organ. 1999;77(7):545-52.
14. Mer'Awi A, Tesfaye T. Measles outbreak in Simada District, South Gondar Zone, Amhara Region, May-June 2009: Immediate need for strengthened routine and supplemental immunization activities (SIAs) Ethiop J Health Dev. 2012;26(2):115-18.

15. Akinola F, Ayodeji A, Adeniyi F. Epidemiology of measles in Southwest Nigeria: an analysis of measles case-based surveillance data from 2007 to 2012. Trans R Soc Trop Med Hyg. 2014;108:13340.

16. The Law on Protection of population from Infectious Diseases. Rulebook on implementation of mandatory immunization, immunoprophylaxis and chemoprophylaxis against infectious diseases and persons subject to this obligation. Official Paper of of FBA, no. 22/07, 19/08, 6/10, 8/11, $12 / 12,95 / 13,64 / 14$ and 16/15.

17. World Health Organisation. Progress towards measles control in WHO's African Region, 2001-2008. Wkly Epidemiol Rec. 2009;84(39):397-04.

18. World Health Organisation. Manual for the laboratory diagnosis of measles and rubella virus infection. 2nd edn. Geneva: WHO; 2007.

19. European surveillance for selected vaccine-preventable diseases (EUVAC). Annual measles report 2010. [updated 2011 Apr 8; cited 2011 Apr 21]. Available from: http://www.euvac.net/graphics/euvac/pdf/annual_2010.pdf. 